\title{
Preferências da população de diferentes estratos sociais no manejo das águas pluviais urbanas
}

\author{
Population of different social strata and its preferences \\ in urban stormwater management
}

\section{Rutinéia Tassi \\ Daniel Gustavo Allasia Piccilli \\ Santiago Chaves Brancher \\ Carlos Augusto Roman}

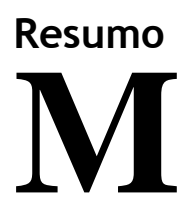

uitos municípios brasileiros possuem legislação específica voltada para o manejo das águas pluviais no meio urbano, tendo como principal objetivo a redução do escoamento superficial. Entre as medidas promovidas se encontra a obrigatoriedade de implantação de diferentes dispositivos nos lotes que funcionem armazenando ou infiltrando o excesso do escoamento superficial causado pela urbanização, de forma a compensar o impacto desta. Esse tipo de prática é conhecido como técnica compensatória (TC). Diante das diferentes TC que podem ser escolhidas, neste artigo são apresentadas as preferências e principais percepções da população de três diferentes estratos socioeconômicos a respeito das TCs. O estudo foi conduzido na cidade de Santa Maria, RS, que como outros municípios brasileiros de médio porte, ainda deverá adotar algum tipo de política pública voltada para a gestão das águas pluviais no meio urbano. Foram entrevistadas 518 residências em bairros representativos da baixa classe alta, alta classe média e baixa classe média, que possuem a mesma diretriz para ocupação do solo. Os resultados revelaram importantes aspectos a respeito do entendimento dos entrevistados no que se refere ao manejo das águas pluviais em meio urbano e evidenciaram que a preferência por TC de armazenamento ou infiltração pode ser influenciada pela classe socioeconômica. Ainda, a entrevista permitiu identificar que em mais de $90 \%$ dos domicílios entrevistados já existe conhecimento sobre esse tipo de política pública.

Palavras-chaves: Águas pluviais. Gerenciamento. Legislação. Técnica compensatória. Controle do escoamento. Aproveitamento de água da chuva.

Rutinéia Tassi Universidade Federal de Santa Maria Santa Maria - RS - Brasil

Daniel Gustavo Allasia Piccilli Universidade Federal de Santa Maria Santa Maria - RS - Brasil

Santiago Chaves Brancher Universidade Federal de Santa Maria Santa Maria - RS - Brasil

Carlos Augusto Roman Universidade Federal de Santa Maria Santa Maria - RS - Brasil

Recebido em 01/09/15 Aceito em 07/01/16

\section{Abstract}

Many Brazilian municipalities have specific legislation focused on the management of urban stormwater with the main purpose runoff control. Among the promoted measures are the mandatory implementation of different devices that operate storing or infiltrating the runoff, compensating its impact. This practice is known as compensatory technique (CT). Given the different possible CT that can be chosen, this article presents the main preferences and perceptions of the population in three different socioeconomic groups. The study was accomplished in the city of Santa Maria / RS, that as other municipalities of medium size, should also adopt some sort of public policy towards the stormwater management. A total of 518 households were surveyed in representative districts of the upper lower class, upper middle class and lower middle class, who have the same guideline for land use. The results revealed important aspects regarding the understanding of the public to the management of rainwater in urban areas, and showed that the preference between storage or infiltration may be influenced by socioeconomic status. In addition, the survey was able to identify that more than $90 \%$ of households have already knowledge about this type of public policy.

Keywords: Stormwater. Management. Legislation. Best management practice. Runoff control. Rainwater harvesting.

TASSI, R.; ALLASIA PICCILLI, D. G.; BRANCHER, S. C.; ROMAN, C. A. Preferências da população de diferentes estratos 39 sociais no manejo das águas pluviais urbanas. Ambiente Construído, Porto Alegre, v. 16, n. 3, p. 39-52, jul./set. 2016. ISSN 1678-8621 Associação Nacional de Tecnologia do Ambiente Construído.

http://dx.doi.org/10.1590/s1678-86212016000300091 


\section{Introdução}

O crescimento populacional no Brasil tem sido significativo ao longo das últimas décadas, concentrando-se principalmente nos grandes centros urbanos, onde o processo de urbanização, na maioria das vezes, ocorre de forma desordenada e irregular, conduzindo a sucessivos problemas em relação aos processos hidrológicos, especialmente aqueles relacionados ao escoamento superficial das águas pluviais.

O natural escoamento das águas pluviais é alterado em razão da impermeabilização do solo, decorrente da construção de edificações, ruas, calçadas, entre outros. A parcela de água que antes infiltrava ou evaporava passa a escoar superficialmente, aumentando as áreas potencialmente alagáveis (GEIGER, 1993; GENZ, 1994; CANHOLI, 1995; TUCCI, 2001; TASSI, 2002).

Tradicionalmente, na maior parte dos municípios brasileiros, a estratégia utilizada para a mitigação desse problema consiste em drenar esse escoamento pluvial através de uma rede de drenagem devidamente projetada até um coletor principal, córrego ou rio urbano. Assim, o volume que ficava armazenado no solo e depressões naturais do terreno passa a escoar por superfícies com menor rugosidade e em canalizações com alta eficiência hidráulica, resultando em aumento da velocidade e do volume escoado superficialmente para jusante.

Esse processo traz como consequências o acréscimo e a antecipação nos picos das vazões que chegam aos corpos hídricos, além do aumento da capacidade de transporte de sedimentos, o que causa, ou mesmo agrava, os problemas de inundações a jusante (TUCCI; PORTO; BARROS, 1995), comprometendo também a qualidade da água. Assim, obras de canalização para a condução do escoamento pluvial para jusante podem solucionar o problema de drenagem do local; no entanto, em muitos casos, essa simples transferência pode dar origem a novos problemas, especialmente em razão da falta de capacidade de comportar os novos volumes oriundos da região de montante.

Além disso, como o processo de urbanização normalmente é contínuo, tanto os volumes escoados quanto as vazões aumentam constantemente, sendo necessárias novas ampliações das redes de drenagem pluvial urbana, por não mais suportarem os excedentes gerados. Tornam-se necessárias, portanto, obras de drenagem cada vez maiores, que, em alguns casos, podem ser inviáveis devido aos altos custos envolvidos e às limitações físicas de espaço para ampliação do sistema.

Diante da insustentabilidade desse processo, algumas cidades brasileiras estão substituindo as tradicionais obras de ampliação, ou de implantação de redes de drenagem, por técnicas que buscam atenuar os impactos da urbanização no escoamento natural das águas pluviais, conhecidas no Brasil como técnicas compensatórias (BAPTISTA; NASCIMENTO; BARRAUD, 2011).

Como princípio, nesse tipo de técnica procura-se o tratamento ao escoamento pluvial o mais próximo possível da fonte geradora, por meio de dispositivos que promovam a infiltração, percolação, evapotranspiração e/ou amortecimento das águas pluviais geradas pela impermeabilização, com a finalidade de diminuir as vazões de pico e retardar os volumes escoados superficialmente. Entre as técnicas compensatórias (TC) mais conhecidas no Brasil destacam-se a aplicação de trincheiras de infiltração, pavimentos permeáveis, telhados verdes e reservatórios de detenção nos lotes.

As trincheiras de infiltração (Figura 1a), as biorretenções (Figura 1b), os poços de infiltração (Figura 1c), as valas de infiltração (Figura 1d) e os pavimentos permeáveis (Figura 1e) são estruturas dimensionadas para receber o escoamento superficial, em geral de áreas impermeabilizadas, evitando que esse atinja o sistema de drenagem pluvial. Com exceção do poço de infiltração, os dispositivos são preenchidos total ou parcialmente com material granular, como brita e seixos, envolto em manta de geotêxtil, que funciona como um filtro aos poluentes presentes na água pluvial. $\mathrm{O}$ volume de vazios no interior dessas estruturas deve ser suficiente para o armazenamento da água durante os eventos chuvosos, e o esvaziamento se dá mediante a infiltração da água no solo para camadas mais profundas, e também por evapotranspiração, no caso da biorretenção. Dessa forma, os efeitos obtidos quando esses dispositivos são utilizados são a redução das vazões de pico escoadas no sistema de drenagem, a redução do volume de escoamento superficial e a recarga do lençol freático. Essas estruturas podem ser construídas junto às residências e estacionamentos, e ao longo de ruas e avenidas, e possuem potencial paisagístico, ou seja, podem ser facilmente integradas à paisagem (WOODS-BALLARD et al., 2007).

Os reservatórios de detenção nos lotes (Figura 1f) são utilizados para promover o armazenamento temporário dos volumes escoados a partir de 
superfícies impermeáveis, reduzindo a vazão de pico escoada para o sistema de drenagem pluvial. Após o evento chuvoso, o reservatório deve ser esvaziado para garantir seu funcionamento em eventos subsequentes. Isso normalmente é realizado por meio de um descarregador de fundo/orifício, dimensionado para garantir que o esvaziamento ocorra lentamente, de maneira a garantir a redução da vazão de pico desejada (WAVERLEY..., 2014). Esse tipo de estrutura possibilita a posterior utilização da água armazenada para fins não potáveis, devendo, para isso, ser conduzida a um outro sistema de reservação.

A utilização das TC vai ao encontro dos princípios empregados no desenvolvimento de muitos planos diretores de drenagem urbana (PDDU) e planos municipais de saneamento básico (PMSB), instituídos pela Lei Federal n. 11.445/2007 (BRASIL, 2007) e previamente citados no Estatuto das Cidades, conforme Lei Federal n. 10.257/2001 (BRASIL, 2001). Nesses documentos verifica-se que há forte recomendação com relação à adoção de práticas que preservem/mantenham as condições naturais de escoamento em uma bacia hidrográfica que passa por um processo de urbanização.
Nesse sentido, verifica-se que, de forma gradativa, algumas prefeituras brasileiras vêm criando algum tipo de mecanismo legal para que o manejo do escoamento pluvial seja efetivado em âmbito municipal seguindo os princípios das TC. De modo geral, a maioria das cidades brasileiras que possuem algum tipo de legislação a esse respeito foca sua aplicação especialmente em novos empreendimentos. Entre as cidades pioneiras nessa regulamentação citam-se como exemplos as cidades de Belo Horizonte, Porto Alegre e São Paulo (BAPTISTA; NASCIMENTO; BARRAUD, 2011).

Assim, este artigo apresenta as percepções e preferências da população em relação à implementação de TC em legislação específica para o controle do escoamento pluvial no meio urbano. Os resultados apresentados são o produto de um estudo realizado na área urbana da cidade de Santa Maria, no estado do Rio Grande do Sul, e refletem a opinião de moradores de 518 residências, compreendidas em três diferentes estratos socioeconômicos, o que permitiu identificar também como a condição socioeconômica pode influenciar na aceitabilidade das TC.

\section{Figura 1 - Exemplos de técnicas compensatórias}

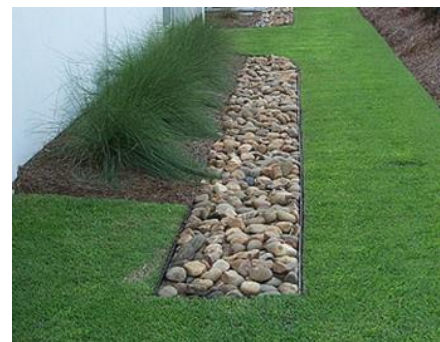

(a) Trincheira de infiltração

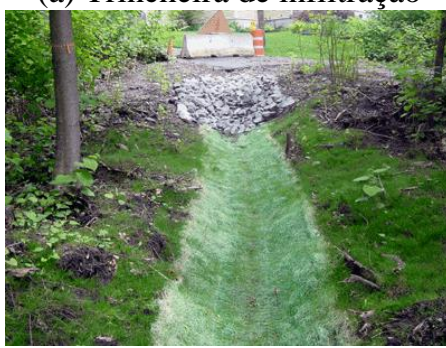

(d) Vala de infiltração

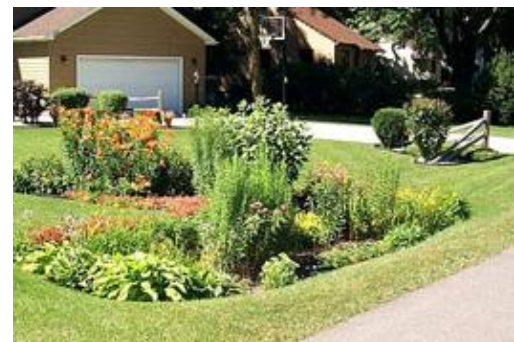

(b) Biorretenção

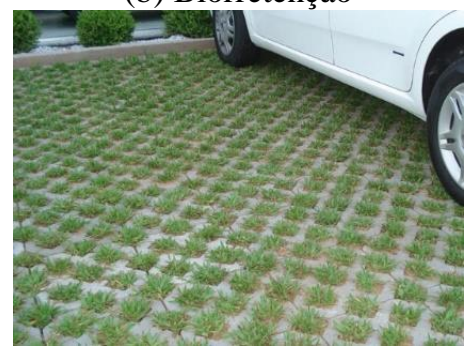

(e) Pavimento permeável

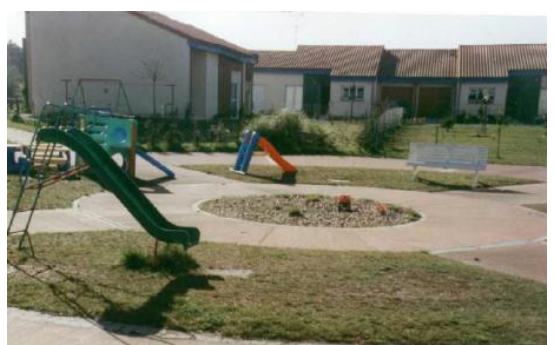

(c) Poço de infiltração

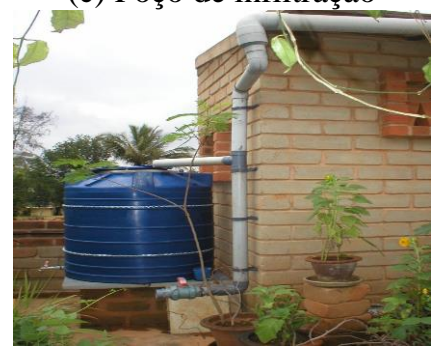

(f) Reservatório de detenção

Fontes: (a) Inti (2012); (b) State of Tenessee (2012); (c) e (f) acervo dos autores; (d) RiverSides (2012); e (e) Rhinopisos (2012). 


\section{Aspectos legais sobre a destinação das águas pluviais no Brasil}

A Política Nacional de Saneamento Básico, instituída pela Lei Federal n. 11.445/2007 (BRASIL, 2007), estabelece as diretrizes relacionadas ao manejo das águas pluviais urbanas, que visam incentivar o aproveitamento das águas pluviais, o que se destaca como uma ação positiva para o controle de cheias e a preservação ambiental. Embora essa legislação seja recente, verifica-se que um grande número de cidades brasileiras, especialmente as capitais, vem há anos desenvolvendo legislações específicas para o tratamento do escoamento pluvial no meio urbano, notadamente aquele gerado nos lotes. Assim, o uso de estruturas de pequeno porte para o controle do escoamento pluvial na escala de lote é crescente no Brasil, sendo previsto, recomendado ou obrigatório na legislação de diversos municípios brasileiros (DRUMOND; COELHO; MOURA, 2011).

Em Belo Horizonte, MG, a Lei Municipal n. 7.166/1996 (BELO..., 1996), de parcelamento, ocupação e uso do solo da cidade, tornou obrigatória a construção de pequenos reservatórios para as construções que impermeabilizarem o solo do terreno acima das taxas de permeabilidade definidas para o município, com o objetivo de retardar o lançamento das águas pluviais na rede pública. O volume do reservatório deve comportar $30 \mathrm{~L} / \mathrm{m}^{2}$ de área impermeabilizada acima do limite estabelecido em lei.

$\mathrm{Na}$ cidade de Porto Alegre, RS, o Decreto Municipal n. 18.611/2014 (PORTO..., 2014) define que toda nova ocupação urbana deverá considerar a aplicação do conceito de desenvolvimento urbano de baixo impacto, por meio da implantação de técnicas que privilegiem a infiltração e a reservação das águas pluviais. Esse decreto também estabelece que todo parcelamento do solo deverá prever em sua implantação como limite de vazão máxima de saída para a rede pública de águas pluviais um valor menor ou igual a $20,8 \mathrm{~L} /$ (s.ha).

A Lei Municipal n. 13.276/2002 da cidade de São Paulo (SÃO..., 2002) torna obrigatória a execução de reservatório para armazenar as águas pluviais coletadas em coberturas e pavimentos nos lotes, edificados ou não, que tenham área impermeabilizada superior a $500 \mathrm{~m}^{2}$. Para isso devem ser executados reservatórios para acumulação das águas pluviais como condição para a obtenção do certificado de conclusão ou auto de regularização. As águas da chuva captada por telhados, coberturas, terraços e pavimentos descobertos devem ser conduzidas a um reservatório. Essa água armazenada deverá preferencialmente infiltrar-se no solo, podendo ser despejada na rede pública de drenagem após $1 \mathrm{~h}$ de chuva ou ser conduzida para outro reservatório para ser utilizada para finalidades não potáveis na edificação.

Nos municípios do Rio de Janeiro, RJ - Decreto Municipal n. 23.940/2004 (RIO..., 2004), Ponta Grossa, PR - Decreto Municipal n. 7.673/2013 (PONTA..., 2013), Matão, SP - Lei Municipal n. 4.520/2012 (MATÃO, 2012), Recife, PE - Lei Municipal n. 18.011/2014 (RECIFE, 2014), João Pessoa, PB - Lei Municipal n. 10.479/2005 (JOÃO..., 2005), e Manaus, AM - Lei Municipal n. 1.192 (MANAUS, 2007), entre outros, são fornecidas diretrizes bastante similares às utilizadas no município de São Paulo com relação à gestão das águas pluviais.

Esses exemplos de legislação/decreto possuem como foco principal o manejo da água pluvial no espaço urbano, apresentando ações voltadas especialmente ao controle de cheias, embora a legislação de muitos municípios siga o exemplo daquela de São Paulo e oriente também no sentido do aproveitamento das águas pluviais para fins não potáveis nas edificações. Esse tipo de incentivo é uma resposta aos problemas relacionados à superexplotação dos mananciais de água e ao comprometimento de sua qualidade. Assim, a introdução de planos de uso racional da água e de estratégias para a redução do consumo em todos os setores tem aumentado nos últimos anos (AMORIM; PEREIRA, 2008).

Ainda, de maneira independente, vários estados e o Distrito Federal (SÃO..., 2007; ALAGOAS, 2014; PARAÍBA, 2010; DISTRITO..., 2008), além de cidades brasileiras (FORTALEZA, 2013; SALVADOR, 2010; GUARULHOS, 2009; PORTO..., 2008; CASCAVEL, 2007; CURITIBA, 2006; MARINGÁ, 2003) criaram programas de conservação de água (PCA) nas edificações (HAFNER, 2007; SANTOS et al., 2006; SAUTCHÚCK, 2004). O PCA sugere que a racionalização no consumo de água tratada pode ser atingida mediante um conjunto de intervenções sistemáticas a serem realizadas em uma edificação, que garantam sempre a qualidade e a quantidade de água para o consumo. Nesse conjunto de intervenções, o PCA sugere que tanto as edificações residenciais quanto as públicas utilizem hidrômetros individuais, substituam e/ou adaptem torneiras e chuveiros antigos para a minimização do consumo de água, e captem e aproveitem a água da chuva (CAAC) para usos não potáveis nas edificações, entre outras intervenções. $\mathrm{O}$ incentivo à CAAC por parte do gestor está

42 Tassi, R.; Allasia Piccilli, D. G.; Brancher, S. C.; Roman, C. A. 
plenamente justificado no contexto de sustentabilidade e das atuais políticas públicas de desenvolvimento urbano, tendo em vista que essas medidas diminuem os custos com captação e tratamento de água, e promovem a conservação de mananciais.

No entanto, o arcabouço legal mencionado, tanto para o controle de cheias como para a preservação de mananciais, será efetivo somente se acolhido e cumprido pela população. Nesse sentido, são necessários mais estudos a respeito da disposição da população brasileira à implementação de técnicas como as compensatórias, especialmente no que diz respeito àquelas práticas que seriam preferenciais no caso da exigência legal.

\section{Metodologia}

A estratégia metodológica adotada foi baseada na seleção de bairros representativos de diferentes estratos socioeconômicos do município de Santa Maria e na realização de entrevistas em domicílios amostrados, com posterior processamento descritivo dos dados. Uma melhor descrição do procedimento é apresentada na sequência do texto.

\section{Características do local de estudo e seleção de áreas representativas para a entrevista}

De acordo com dados do IBGE (INSTITUTO..., 2010), em 2010 a população santamariense foi estimada em mais de 261 mil habitantes, distribuída em 41 bairros. $\mathrm{Na}$ ocasião, a renda média mensal da população economicamente ativa era de $\mathrm{R} \$ 1.554,00$, sendo entre os bairros a menor e a maior renda média mensal de $\mathrm{R} \$ 628,00$ e de $\mathrm{R} \$ 3.087,00$ respectivamente.

O município de Santa Maria está dividido em dez distritos, sendo o $1^{\circ}$ Distrito (Sede Municipal) o alvo deste estudo, pois representa o perímetro urbano municipal de acordo com a Lei Complementar n. 33/2005 (SANTA..., 2005). Nesse perímetro estão compreendidas as áreas já urbanizadas e as áreas sujeitas à expansão urbana e ao parcelamento do solo para urbanização.

Considerando a região definida pelo $1^{\circ}$ Distrito, foram selecionados como unidades amostrais três bairros representativos de diferentes estratos socioeconômicos do município de Santa Maria, identificados pelo grupo de renda da população, de acordo com a classificação apresentada pela Secretaria de Assuntos Estratégicos (SAE) (BRASIL, 2012). Embora diferentes do ponto de vista socioeconômico, esses três bairros possuem em comum valores próximos de índice de ocupação (IO) do solo (relação entre a projeção no plano horizontal da área ocupada pela edificação e a área total do terreno), instituídos pela Lei Complementar n. 072/2009 (SANTA..., 2009). Para a identificação desses bairros foram utilizados dados levantados no censo de 2010 (IBGE, 2010), a Lei Complementar n. 072/2009 (SANTA..., 2009), análise de imagens de satélite e visitas de campo.

A igualdade do IO nos três bairros garantiu que a avaliação fosse realizada considerando-se apenas a opinião dos entrevistados dentro de cada estrato socioeconômico a respeito de sua preferência quanto às TC apresentadas durante a entrevista, já que as exigências sob o ponto de vista de ocupação do solo seriam semelhantes.

Para a escolha dos locais de entrevista, foi realizado um trabalho preliminar de identificação com o auxílio de imagens de satélite. Essas imagens permitiram avaliar condições de acessibilidade e o padrão de ocupação, já que se buscava maior representatividade de regiões com edificações unifamiliares. A partir dessas análises, foram selecionados, inicialmente, três bairros que representariam os estratos socioeconômicos desejados para o estudo. $\mathrm{Na}$ sequência, foi realizada uma visita in loco para verificar se as percepções espaciais estavam de acordo com a verdade de campo e para atestar condições de acessibilidade e segurança no processo de entrevista. Também foi realizada uma tentativa de identificação de problemas relacionados diretamente à gestão das águas pluviais no espaço urbano de cada bairro.

Seguindo esses critérios, foram escolhidos os bairros Nossa Senhora de Lourdes, Camobi e Urlândia. Os principais indicadores dos bairros selecionados estão apresentados na Tabela 1 , sendo o IO de 0,55 para as três unidades amostrais, e na Figura 2 é apresentada uma representação espacial da localização dos bairros dentro do $1^{\circ}$ Distrito de Santa Maria. 
Tabela 1 - Indicadores socioeconômicos dos bairros selecionados para amostragem

\begin{tabular}{l|c|c|c|c|c}
\hline Bairro & $\begin{array}{c}\text { População com } \\
\text { mais de 10 anos } \\
\text { (habitantes)* }\end{array}$ & $\begin{array}{c}\text { Domicílios } \\
\text { (unidades)* }\end{array}$ & $\begin{array}{c}\text { Densidade } \\
\text { populacional } \\
\text { (hab./ha) }\end{array}$ & $\begin{array}{c}\text { Densidade } \\
\text { habitacional } \\
\text { (un./ha) }\end{array}$ & $\begin{array}{c}\text { Renda média } \\
\text { mensal dos } \\
\text { domicílios (R\$)* }\end{array}$ \\
\hline N.S.Lourdes & 5.499 & 2.217 & 36,66 & 14,78 & $5.461,77$ \\
Camobi & 13.383 & 7.279 & 6,53 & 3,56 & $3.226,38$ \\
Urlândia & 7.663 & 2.846 & 27,37 & 10,16 & $1.537,22$ \\
\hline
\end{tabular}

Fonte: *Instituto Brasileiro de Geografia e Estatística (2010).

Figura 2 - Identificação dos bairros utilizados no estudo dentro da área do $1^{\circ}$ Distrito do Município de Santa Maria

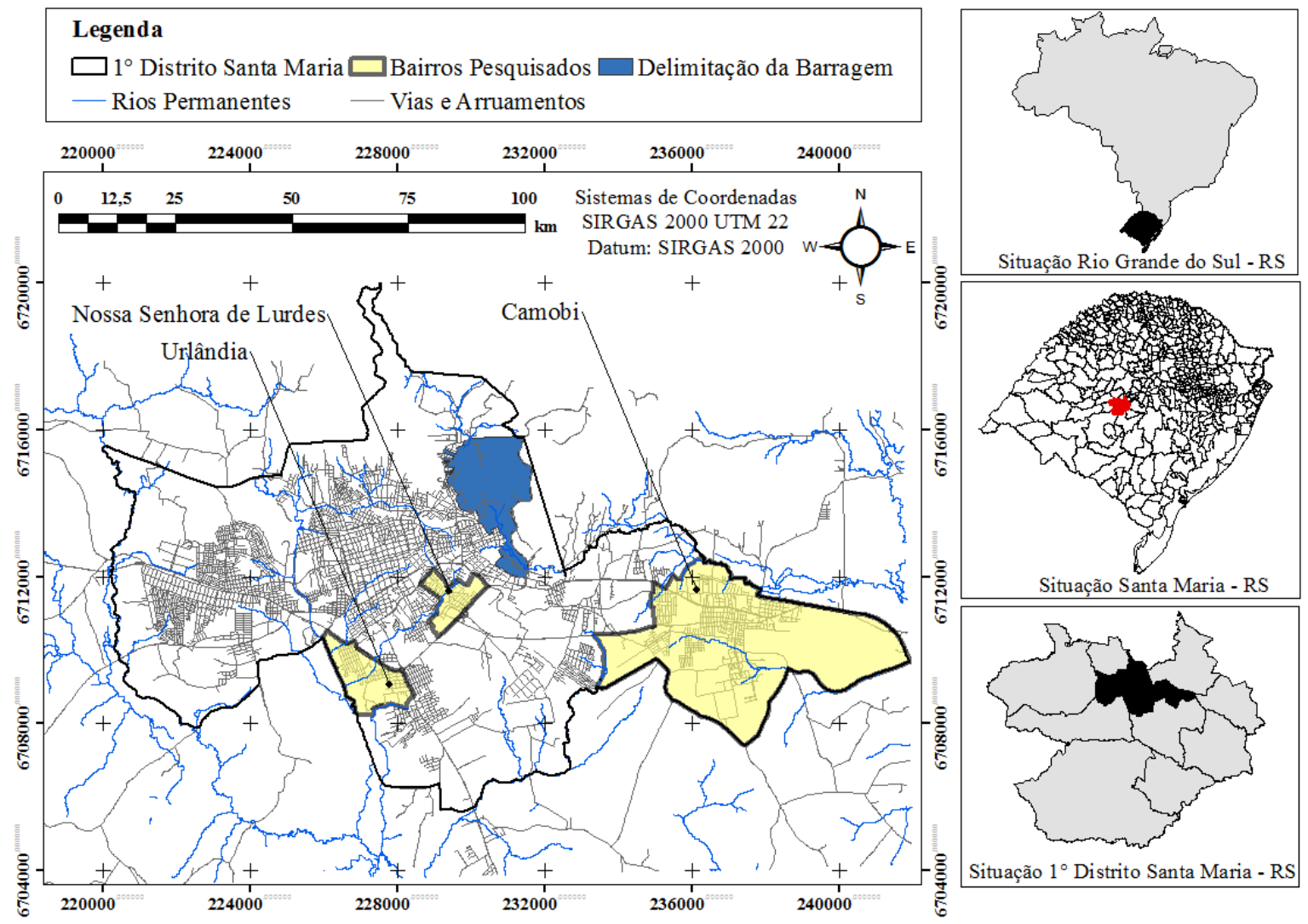

O bairro Nossa Senhora de Lourdes possui uma área de aproximadamente $1,5 \mathrm{~km}^{2}$, o que equivale a $1,20 \%$ do $1^{\circ}$ Distrito. Seguindo o critério de classes econômicas da SAE, a renda média mensal dos domicílios particulares do bairro Nossa Senhora de Lourdes é representativa de uma parcela da população considerada de baixa classe alta. As edificações na região são predominantemente unifamiliares, com algum espaço de jardim no recuo frontal da edificação, e uma grande maioria de casas com piscina no jardim de fundos.

O bairro é atravessado por um curso d'água (arroio Cancela), que ainda possui parte de seu trecho em leito natural, embora a principal travessia ao longo do bairro esteja canalizada. Durantes intensos eventos chuvosos é comum o alagamento na região de fundo de vale do arroio, pois há o extravasamento do arroio no leito natural, e a capacidade hidráulica do trecho canalizado não é suficiente para a drenagem adequada das águas pluviais, o que também provoca alagamentos difusos. Além desses aspectos, a região é bastante declivosa, e a velocidade da água nas ruas atinge valores que podem trazer risco aos pedestres e veículos que transitam no local; durante eventos chuvosos é comum os motoristas evitarem transitar pelo bairro.

O bairro Camobi é o mais populoso do município de Santa Maria e é representativo da alta classe média, de acordo com a SAE. Este bairro possui uma área de $20,5 \mathrm{~km}^{2}$, o que representa $16,8 \%$ 
do distrito-sede, sendo entre os três bairros estudados o menos povoado (população/área). Neste bairro predominam as edificações unifamiliares, sendo possível encontrar diferentes padrões de edificações, podendo-se dizer que há uma mescla entre residências simples e outras mais abastadas; também é possível encontrar, em menor proporção, pequenos edifícios plurifamiliares.

O bairro é bastante plano, e somente poucas regiões possuem redes de drenagem pluvial, que acabam recebendo clandestinamente o esgotamento sanitário, devido à inexistência desse sistema na maioria do bairro. Onde não existe rede de drenagem pluvial, o escoamento ocorre em valas a céu aberto, o que gera forte pressão sobre o poder público para a execução de obras para sua canalização. Diante desse cenário, durante eventos chuvosos é bastante comum a ocorrência de alagamentos localizados.

O bairro Urlândia é classificado como de baixa classe média, com residências de pequeno porte, de padrão popular e condições de saneamento básico bastante precárias. A área do bairro é de aproximadamente $2,8 \mathrm{~km}^{2}$, o que representa $2,28 \%$ da área do distrito-sede de Santa Maria. Este bairro tangencia a oeste a porção de jusante do arroio Cadena, que é o principal curso da água da cidade de Santa Maria. Esse curso d'água atravessa diversos bairros, e é comum o extravasamento de água para a planície durante eventos críticos, o que acaba gerando inundações.

\section{Determinação da amostra}

Para a determinação do tamanho amostral foi empregado um método probabilístico de amostragem aleatória estratificada, que consiste em selecionar em cada estrato uma amostra aleatória simples sem reposição.

Neste estudo, cada bairro representa um subgrupo amostral, em função da classe socioeconômica. Para cada um dos estratos (representados pelos três bairros) foi determinado seu peso relativo (\%) com relação à população (número total de domicílios) utilizada no estudo. Na sequência, foi realizado o procedimento de amostragem aleatória simples sem reposição para escolher, na mesma proporção de representatividade na população, o número de sujeitos (número de domicílios) que deveriam integrar a amostra.

Para isso, o percentual de cada estrato foi determinado considerando-se que o número total de domicílios corresponde a 1.500 unidades habitacionais, o que representa cerca de $30 \%$ dos domicílios nesses bairros com IO de 0,55. Para a determinação desse número de domicílios em cada bairro sob o mesmo IO, foi realizado um trabalho de análise de imagens de satélite, em que foram identificadas e contadas as edificações construídas dentro de uma mesma zona de IO.

O tamanho da amostra $(\eta)$ para o processo de amostragem aleatória simples foi determinado seguindo o procedimento aplicado para populações finitas (Eq. 1):

$n=\frac{N \cdot \hat{p} \cdot \hat{q} \cdot(\vartheta)^{2}}{\hat{p} \cdot \hat{q} \cdot(\vartheta)^{2}+(N-1) \cdot E^{2}}$

Eq. 1

Sendo:

$\mathrm{N}$ a população de cada estrato;

$\vartheta$ igual a 1,96 para o nível de confiança de $95 \%$;

$\hat{p}$ a porcentagem com a qual o fenômeno ocorre $(50 \%)$;

$\hat{q}$ a porcentagem complementar igual a $1-\hat{p} ; \mathrm{e}$

E o erro amostral máximo permitido, assumido como $10 \%$ neste estudo.

A Tabela 2 apresenta uma síntese dos valores resultantes a serem utilizados na análise.

Assim, ficou estabelecido que o número total de edificações a serem entrevistadas é de 518, correspondente ao somatório do total de cada bairro. Para a realização das entrevistas em cada estrato, foi analisada a distribuição de residências a serem entrevistadas, da maneira mais uniforme possível, buscando uma amostragem com boa representatividade espacial dentro da região da IO.

Tabela 2 - Síntese dos dados domiciliares utilizados no processo amostral

\begin{tabular}{c|c|c|c|c}
\hline Bairro & $\begin{array}{c}\mathbf{N}^{\mathbf{0}} \text { de } \\
\text { edificações } \\
\text { na zona de } \\
\mathbf{I O = 0 , 5 5}\end{array}$ & $\begin{array}{c}\text { Percentual } \\
\text { do estrato } \\
\text { na amostra } \\
\mathbf{( \% )}\end{array}$ & $\begin{array}{c}\mathbf{N}^{\mathbf{0}} \text { de domicílios } \\
\text { de cada estrato } \\
\text { na amostra de } \\
\mathbf{1 . 5 0 0}\end{array}$ & $\begin{array}{c}\mathbf{N}^{\mathbf{0}} \text { de edificações } \\
\text { na amostragem } \\
\text { aleatória simples }\end{array}$ \\
\hline Nossa Senhora de Lourdes & 181 & 3 & 52 & 46 \\
Camobi & 3.875 & 72 & 1.080 & 284 \\
Urlândia & 1.292 & 25 & 368 & 188 \\
\hline
\end{tabular}




\section{Elaboração e aplicação do questionário}

Foi elaborado um questionário de caráter qualitativo que objetivou avaliar as preferências dos entrevistados e as principais percepções a respeito de políticas públicas voltadas para o manejo das águas pluviais no meio urbano. Procurou-se a elaboração de um questionário curto, para não aborrecer o entrevistado, com uma linguagem bastante simples, buscando minimizar a possibilidade de respostas incertas devido a uma má interpretação.

Ao mesmo tempo, procurou-se manter a objetividade nas perguntas e a clareza sobre o assunto abordado. Além do questionário, recursos gráficos como fotografias também foram utilizados, de maneira a elucidar as situações apresentadas no questionário. A elaboração do questionário e a seleção de imagens contou com a colaboração de professores com especialidade na área de drenagem pluvial e de gestão dos recursos hídricos, além de alunos dos cursos de graduação em Engenharia Civil e Engenharia Sanitária e Ambiental, todos da Universidade Federal de Santa Maria. O questionário elaborado possui quatro perguntas, conforme esquematicamente apresentado no Quadro 1.
$\mathrm{Na}$ primeira questão apresenta-se a situação hipotética de a cidade de Santa Maria passar a exigir um sistema de controle de escoamento pluvial no lote e questiona-se o entrevistado a respeito de sua preferência sobre uma técnica compensatória. Nessa questão as TC foram separadas em dois grupos: o primeiro grupo prevê a captação e o posterior aproveitamento das águas pluviais (alternativa a); o segundo grupo contempla as demais estruturas (alternativa b). Optou-se pela realização dessa separação porque se suspeitou que a opção pela alternativa (a), por exemplo, estaria fortemente relacionada à visualização de um possível benefício econômico, já que é o único dispositivo que permite o aproveitamento direto da água captada, diferentemente das demais opções.

$\mathrm{Na}$ segunda questão são apresentadas diferentes possibilidades de TC, que funcionam mediante o princípio da infiltração e que são mencionadas na legislação de muitos municípios brasileiros. Essa questão foi respondida apenas pelos entrevistados que tivessem escolhido a letra (b) na questão 1. A terceira questão destaca o motivo que levou o entrevistado a escolher a TC, e a quarta questão avalia o grau de conhecimento do entrevistado a respeito do tema.

\section{Quadro 1 - Questionário simplificado aplicado na pesquisa}

1) Se a cidade de Santa Maria, seguindo o exemplo de diversas outras no país, passasse a exigir a implantação de um desses sistemas para o destino das águas da chuva - técnica compensatória - qual você estaria disposto a instalar em sua casa?

(a) Um reservatório que permita aproveitar a água da chuva

(b) Outra técnica compensatória

Se a resposta desta questão for a alternativa (a), passar diretamente para a questão 3 , senão aplicar a questão 2 .

2) Neste caso, qual destes sistemas de técnicas compensatórias você escolheria para implantar na sua edificação se a legislação permitisse a livre escolha?

a) Vala de infiltração

b) Poço de infiltração

c) Trincheira de infiltração

d) Pavimento permeável

e) Vala de biorretenção (biovaleta, jardim de chuva)

3) Qual motivo levou você a escolher este sistema?

a) Estético

b) Maior benefício ambiental que os demais

c) Econômico

d) Outro

4) Você já tinha ouvido falar sobre as políticas públicas voltadas para a gestão da água no meio urbano com foco no controle de cheias?

a) $\mathrm{Sim}$

b) Não

46 Tassi, R.; Allasia Piccilli, D. G.; Brancher, S. C.; Roman, C. A. 
Com o intuito de verificar a primeira versão do questionário elaborado, foi realizada uma amostragem piloto na cidade de Santa Maria com os moradores do bairro Centro. Os resultados numéricos dessas entrevistas foram, portanto, desconsiderados. Ao final dessa etapa preliminar, concluiu-se que o questionário atendeu de forma satisfatória todas as exigências, tais como objetividade, clareza, entendimento e boa aceitação do público. Portanto, o modelo de questionário e a forma como foi feita sua abordagem não sofreram nenhuma alteração.

Durante o processo de entrevista, o entrevistador, devidamente identificado com cartão de aluno da UFSM, primeiramente explicava ao entrevistado o objetivo da pesquisa e apresentava informações relacionadas às atuais políticas públicas para o tratamento das águas pluviais, acompanhadas de exemplos de mecanismos legais utilizados em alguns municípios no Brasil, seguindo a linha das discussões apresentadas na introdução deste artigo. Simultaneamente, eram apresentadas as imagens coloridas (fotografias idênticas àquelas apresentadas na Figura 1) impressas em um cartão, com a identificação dos diferentes sistemas de técnicas compensatórias empregados no Brasil, com uma breve explicação sobre os princípios de funcionamento de cada um deles. Somente após o entrevistado estar satisfeito com os esclarecimentos sobre o assunto, era realizada a aplicação do questionário (modelo do questionário no Quadro 1).

Um aspecto também fundamental no desenvolvimento da metodologia de pesquisa foi a decisão de não abordar com o entrevistado o custo da implantação de cada sistema, devido às possíveis variações de custo entre os sistemas, e até em um mesmo sistema, já que podem ser utilizados diferentes tipos de materiais em sua construção. Imaginou-se também que esse critério poderia influenciar muito na escolha do entrevistado, independentemente de seu poder aquisitivo, que optaria pelo sistema mais barato pela simples obrigação de se adequar a uma nova lei. Sendo assim, apenas quando questionado, o entrevistador expunha o custo de uma maneira apenas comparativa, de acordo com dados apresentados na literatura.

Ao final de cada dia, as respostas das entrevistas eram organizadas na forma de uma planilha eletrônica, para análise e processamento de dados.

\section{Resultados}

A aplicação do questionário desta pesquisa foi realizada entre os dias 6/12/2012 e 3/1/2013, iniciando-se pelo bairro Nossa Senhora de Lourdes e finalizando no bairro Urlândia, sendo entrevistadas 518 residências.

Analisando os dados apresentados na Figura 3a, pôde-se observar que no bairro Nossa Senhora de Lourdes mais da metade das residências entrevistadas $(56 \%)$ preferiu uma técnica compensatória com princípio de funcionamento associado à infiltração (TCI), com relação ao sistema de armazenamento (TCA), que permita o aproveitamento da água da chuva (44\%). Do percentual de entrevistados que optaram por uma técnica compensatória por infiltração, 58\% preferiram uma vala de biorretenção, $19 \%$ a trincheira de infiltração, $12 \%$ o pavimento permeável, e outros $12 \%$ a vala de infiltração (Figura 4a).

Acredita-se que um aspecto determinante para este resultado seja o fato de que a maioria das casas desse bairro já possui em seus pátios sistemas que se assemelham muito com uma vala de biorretenção, ou uma trincheira de infiltração. O quesito "estética" foi muito importante pelos residentes nesse bairro (Figura 5a) na escolha de uma TCI, destacando-se grande rejeição à implantação de um sistema de reservatório para o aproveitamento da água da chuva pela necessidade de alocação de espaço do reservatório e demais elementos de drenagem.

No bairro Nossa Senhora de Lourdes, dos $44 \%$ que indicaram o sistema com aproveitamento de água da chuva, $85 \%$ justificaram essa escolha, respondendo à questão 3 , por acreditarem que esse sistema promoveria maior benefício ambiental que os demais, e apenas $15 \%$ indicaram o benefício econômico nessa justificativa; nenhum dos entrevistados indicou o motivo estético. Ainda, mais de $93 \%$ dos entrevistados nesse bairro responderam afirmativamente à questão 4, o que demonstra conhecimento acerca das atuais políticas de gestão das águas pluviais.

Já no bairro Camobi, 75\% dos entrevistados nas residências optaram pelo sistema de armazenamento que permite o aproveitamento da água da chuva (Figura 3b). Essa preferência foi predominantemente em razão do maior benefício ambiental $(82,3 \%)$ apontado pelos entrevistados, seguido de longe pelo econômico $(13,5 \%)$ e estético $(4,2 \%)$ (Figura 5b). Dos $25 \%$ dos entrevistados que optaram por alguma técnica 
compensatória com infiltração, 62\% responderam vala de biorretenção, $27 \%$ trincheira de infiltração, $7 \%$ pavimento permeável, e $4 \%$ vala de infiltração (Figura 4b). Para 84,5\% dos entrevistados que preferiram uma técnica compensatória com infiltração, a principal razão para essa escolha deve-se ao aspecto estético. A exemplo do resultado encontrado para o bairro Nossa Senhora de Lourdes, 93\% dos entrevistados sinalizaram já ter conhecimento sobre o assunto (questão 4).
No bairro Urlândia, $81 \%$ das residências entrevistadas optaram pela técnica compensatória de armazenamento com aproveitamento da água da chuva, e $19 \%$ por alguma técnica compensatória com infiltração (Figura 3c). Com relação a essa marcante preferência, neste bairro o motivo econômico (mencionado como economia com consumo de água tratada) foi notadamente o mais apontado na preferência pelo aproveitamento da água da chuva (59\%), seguido pelo motivo ambiental $(31,8 \%)$ e estético $(7,2 \%)$.

Figura 3 - Panorama das respostas dadas à questão 1 em cada bairro sobre que técnica compensatória o entrevistado estaria disposto a instalar na edificação, se técnica compensatória com infiltração (TCl) ou técnica compensatória com armazenamento (TCA)

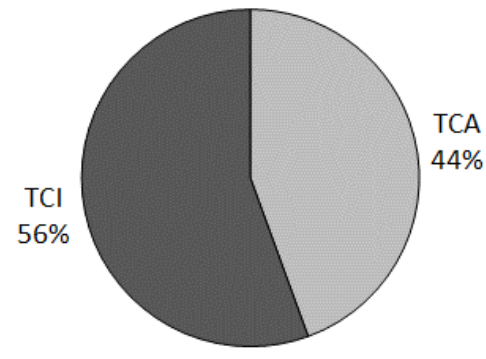

(a) Nossa Senhora de Lourdes

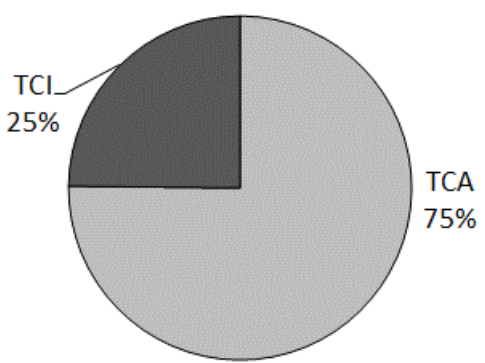

(b) Camobi

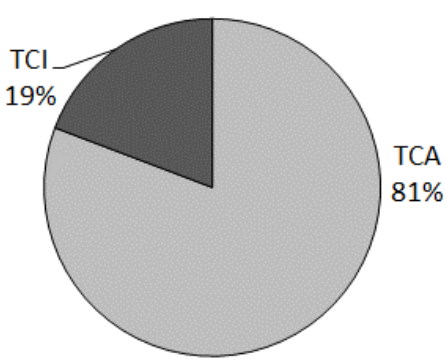

(c) Urlândia

Figura 4 - Panorama das respostas dadas à questão 2 por bairro sobre a opção pela técnica compensatória de infiltração $(\mathrm{TCl})$, se a legislação permitisse a livre escolha - respondida somente pelos entrevistados que optaram pela $\mathrm{TCl}$ na questão 1

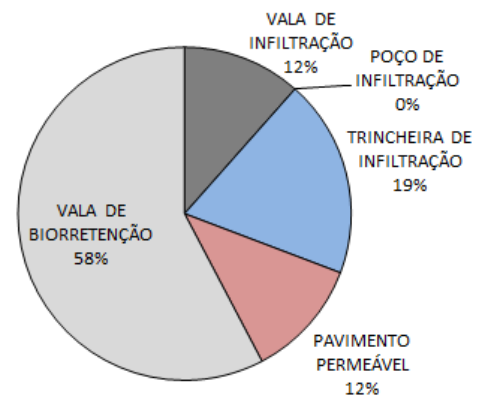

(a) Nossa Senhora de Lourdes

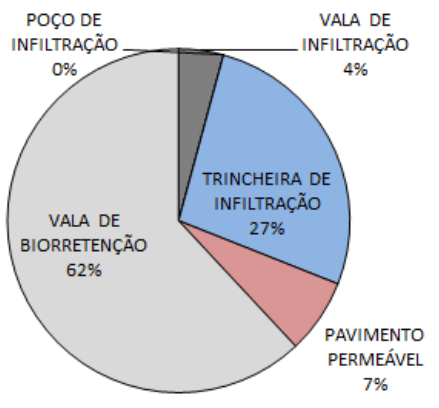

(b) Camobi

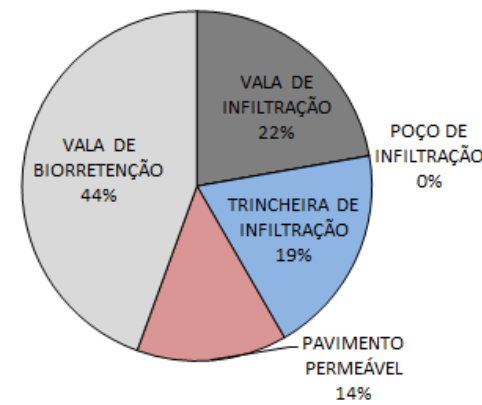

(c) Urlândia

Figura 5 - Panorama das respostas dadas à questão 3 por bairro quando questionado o motivo que levou à escolha do sistema indicado na questão 1

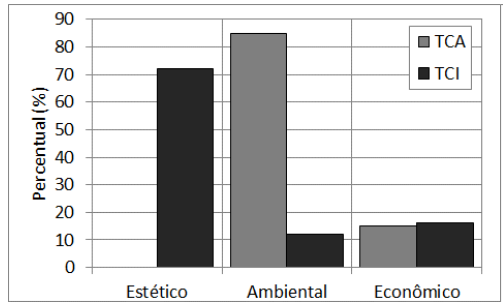

(a) Nossa Senhora de Lourdes

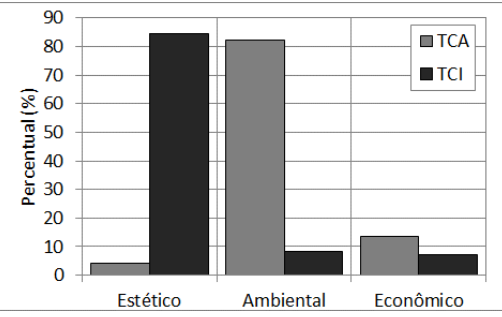

(b) Camobi

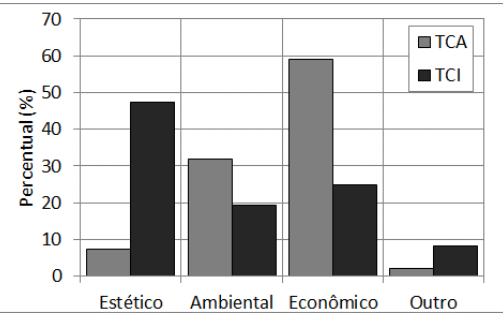

(c) Urlândia

48 Tassi, R.; Allasia Piccilli, D. G.; Brancher, S. C.; Roman, C. A. 
Com relação às técnicas compensatórias com infiltração, $44 \%$ dos entrevistados no bairro Urlândia responderam preferir a vala de biorretenção, $22 \%$ a vala de infiltração, $19 \%$ a trincheira de infiltração, e $14 \%$ o pavimento permeável (Figura 4c). Com relação à justificativa para a escolha da técnica compensatória com infiltração, mais de $47 \%$ dos entrevistados indicaram o motivo estético, seguido pela razão econômica, com $25 \%$ da preferência, e o motivo ambiental, com 19\% (9\% dos entrevistados indicaram outros motivos). Com relação ao conhecimento prévio sobre o assunto abordado, $87 \%$ dos entrevistados neste bairro afirmaram já ter alguma informação a respeito. Durante a aplicação do questionário, foi possível constatar visualmente que a maioria das residências desse bairro não dispunha de um pátio com condições mínimas, principalmente de tamanho adequado, para a implantação de uma técnica compensatória de infiltração, e que mesmo o uso de um sistema de armazenamento demandaria alguma adaptação.

\section{Considerações finais}

Neste trabalho foi possível avaliar as percepções e preferências da população de diferentes estratos socioeconômicos com relação à implementação de técnicas compensatórias, em legislação específica para o controle de cheias. O município de Santa Maria, RS, foi utilizado neste estudo por possuir características representativas de muitos outros municípios brasileiros que ainda deverão adotar algum tipo de política pública voltada para a gestão das águas pluviais no meio urbano.

O trabalho realizado contou com o resultado da entrevista de 518 domicílios do município, em três bairros representativos de diferentes estratos sociais (baixa classe alta, alta classe média e baixa classe média), mas que em comum possuem a mesma exigência legal com relação às taxas ocupação do solo.

Com relação à possibilidade do uso de técnicas compensatórias de armazenamento ou de infiltração, verificou-se que houve marcada preferência pelo sistema de reservação, que permite o aproveitamento de água da chuva, no bairro de menor condição socioeconômica (Urlândia), seguido pelo bairro de classe média (Camobi), enquanto no bairro de classe alta (Nossa Senhora de Lourdes) a preferência da maioria dos entrevistados foi pelo uso de técnicas compensatórias com infiltração.

O motivo econômico na escolha do sistema que permite o aproveitamento de água da chuva teve maior destaque entre os entrevistados do bairro Urlândia, sendo esta razão pouco citada pelos residentes dos outros dois bairros, que ressaltaram maior preocupação ambiental, com menção à preservação de mananciais.

Verificou-se para os três bairros que a opção por uma técnica compensatória com infiltração esteve notadamente relacionada ao apelo estético, sendo a vala de biorretenção o sistema preferido. $\mathrm{O}$ poço de infiltração não foi selecionado por nenhum dos entrevistados, possivelmente pela dificuldade de execução, conforme apontada por alguns entrevistados. No bairro Nossa Senhora de Lourdes foi possível constatar a grande preocupação dos entrevistados com relação à inserção da técnica compensatória no contexto da edificação, de maneira especial com foco no paisagismo.

Ainda, com relação às técnicas compensatórias com infiltração, verificou-se que no bairro Urlândia houve maior dispersão nos resultados relacionados à preferência por um sistema ou outro (vala de biorretenção, trincheira de infiltração, etc.), e também com relação aos benefícios (econômico, ambiental, estético, etc.), comparativamente aos bairros Camobi e Nossa Senhora de Lourdes, que mantiveram o mesmo padrão de preferências. Possivelmente esse resultado esteja associado ao maior percentual de entrevistados com algum conhecimento sobre o assunto, conforme encontrado nestes dois últimos bairros. Merece destaque que, independentemente da classe socioeconômica, mais de $91 \%$ dos entrevistados mostraram algum tipo de conhecimento a respeito de políticas públicas voltadas para o manejo das águas pluviais.

Por fim, com base no resultado dos três bairros, identificou-se que em $74,5 \%$ dos domicílios entrevistados, se os gestores públicos passassem a exigir legalmente a implementação de uma medida para o manejo das águas pluviais em escala de lote, a preferência seria pela implantação de uma técnica compensatória que permitisse o aproveitamento da água da chuva, e $25,5 \%$ optaria por alguma técnica compensatória com infiltração, com grande destaque para um sistema de vala de biorretenção. 


\section{Referências}

ALAGOAS. Lei Estadual n 7.590 , de 25 de março de 2014. Diário Oficial da União, 27 de março de 2014. Disponível em:

<https://www.legisweb.com.br/legislacao/?id=268 421>. Acesso em: 3 mar. 2015.

AMORIM, S. V.; PEREIRA, D. J. A. Estudo Comparativo dos Métodos de Dimensionamento Para Reservatórios Utilizados em Aproveitamento de Água Pluvial. Ambiente Construído, Porto Alegre, v. 8, n. 2, p. 53-66, abr./jun. 2008.

BAPTISTA, M.; NASCIMENTO, N.; BARRAUD, S. Técnicas Compensatórias em Drenagem Urbana. 2. ed. Porto Alegre: Ed. da ABRH, 2011.

BELO HORIZONTE. Lei Municipal $\mathbf{n}^{\circ} \mathbf{7 . 1 6 5}$, de 27 de agosto de 1996. Disponível em: <http://portalpbh.pbh.gov.br/pbh/ecp/comunidade. do? evento=portlet\&pIdPlc=ecpTaxonomiaMenuP ortal\&app=regulacaourbana\&tax $=7936 \&$ lang $=p t$ BR\&pg=5570\&taxp=0\&>. Acesso em: 5 maio 2014.

BRASIL. Classes Sociais no Brasil. SAE Secretaria de Assuntos Estratégicos. 2012. Disponível: <http://www.sae.gov.br/imprensa/saena-midia/veja-diferencas-entre-conceitos-quedefinem-classes-sociais-no-brasil-g1-globo-comem-20-08-2013/>. Acesso em: 23 nov. 2012.

BRASIL. Estatuto da Cidade. Lei 10.257, de 10 de julho de 2001. Presidência da República, 2001. Brasília, DF. Disponível em:

<http://www.planalto.gov.br/ccivil_03/leis/LEIS_2 001/L10257.htm>. Acesso em: 20 ago. 2014.

BRASIL. Lei Federal 11.445, de 5 de janeiro de 2007. Estabelece diretrizes nacionais para o saneamento básico. Presidência da República. 2007. Disponível em:

<http://www.planalto.gov.br/ccivil_03/_ato20072010/2007/lei/111445.htm>. Acesso em: $17 \mathrm{dez}$. 2013.

CANHOLI, A. P. Soluções Estruturais NãoConvencionais em Drenagem Urbana. São Paulo, 1995. 120 f. Tese (Doutorado em Engenharia Civil) - Escola Politécnica, Universidade de São Paulo, São Paulo, 1995.

CASCAVEL. Lei Municipal no 4.631, de 2 de agosto de 2007. Disponível em: <http://www.camaracascavel.pr.gov.br/leismunicipais>. Acesso em: 2 maio 2014.
CURITIBA. Decreto no 293, de 22 de março de 2006, que regulamenta a lei no 10.785 de 2002. Disponível:

<https://www.leismunicipais.com.br/a/pr/c/curitiba /decreto/2006/29/293/decreto-n-293-2006-

regulamenta-a-lei-n-10785-03-e-dispoe-sobre-oscriterios-do-uso-e-conservacao-racional-da-aguanas-edificacoes-e-da-outras-providencias-2006-0322.html>. Acesso: 3 mar. 2015.

DISTRITO FEDERAL. Lei $\mathbf{n}^{\mathbf{0}} \mathbf{4 . 1 8 1}$, de 21 de julho de 2008. Disponível:

<http://www.tc.df.gov.br/SINJ/Arquivo.ashx?id_n orma_consolidado=58170>. Acesso em: 17 jul. 2015.

DRUMOND, P. de P.; COELHO, M. M. L. P.; MOURA, P. M. Análise do Volume de Reservação de Águas Pluviais em Lotes: comparação do caso de Belo Horizonte com outras cidades brasileiras. In: Simpósio Brasileiro de Recursos Hídricos, 19., Maceió, 2011. Anais... Maceió: Ed. da ABRH, 2011.

FORTALEZA. Lei $\mathbf{n}^{\mathbf{0}} \mathbf{1 0 . 0 5 1}$, de 5 de junho de 2013. Disponível em:

<https://www.leismunicipais.com.br/a/ce/f/fortalez a/lei-ordinaria/2013/1006/10051/lei-ordinaria-n10051-2013-obriga-a-instalacao-de-reservatoriose-captadores-de-agua-da-chuva-nos-postos-decombustiveis-e-quaisquer-estabelecimentos-quepossuam-sistema-de-lavagem-de-veiculos>. Acesso em: 15 ago. 2015.

GEIGER, W. F. Concepts for Flood Control in Highly Urbanized Areas. In: INTERNATIONAL CONFERENCE ON URBAN STORM DRAINAGE, Niagara Falls, 1993. Proceedings... Niagara Falls, 1993.

GENZ, F. Parâmetros Para Previsão e Controle de Cheias Urbanas. Porto Alegre, 1994. 162 f. Dissertação (Mestrado em Engenharia Civil) Programa de Pós-graduação em Engenharia de Recursos Hídricos e Saneamento Ambiental, Universidade Federal do Rio Grande do Sul, Porto Alegre, 1994.

GUARULHOS. Lei n⿳0 6.511, de 9 de junho de 2009. Disponível em:

<http://leis.guarulhos.sp.gov.br/06_prefeitura/leis/l eis_download/06511lei.pdf $>$. Acesso em: 3 maio 2014.

HAFNER, A. V. Conservação e Reúso de Água em Edificações: experiências nacionais e internacionais. Rio de Janeiro, 2007. $161 \mathrm{f}$. Dissertação (Mestrado em Engenharia Civil) Programa de Pós-graduação de Engenharia, Universidade Federal do Rio de Janeiro, Rio de Janeiro, 2007. 
INSTITUTO BRASILEIRO DE GEOGRAFIA E ESTATÍSTICA. Censo Demográfico 2010. 2010. Disponível em: 〈http://www.ibge.gov.br>. Acesso em: 10 jul. 2013.

INTI. Inti Contracting LLC. 2012. Disponível em: <http://www.inticontracting.com/exteriorwork.html>. Acesso em: 13 nov. 2012.

JOÃO PESSOA. Lei $\mathbf{n}^{\mathbf{0}} \mathbf{1 0 . 4 7 9}$, de 9 de junho de 2005. Disponível em:

<https://www.leismunicipais.com.br/a/pb/j/joaopessoa/lei-ordinaria/2005/1048/10479/leiordinaria-n-10479-2005-torna-obrigatorio-aexecucao-de-reservatorio-para-as-aguas-coletadaspor-coberturas-e-pavimentos-nos-lotes-edificadosou-nao-que-tenham-area-impermeabilizadasuperior-a-300m2-e-da-outrasprovidencias?q=10479>. Acesso em: 12 ago. 2015.

MANAUS. Lei $\mathbf{n}^{\mathbf{0}} \mathbf{1 . 1 9 2}$, de 31 de dezembro de 2007. Disponível em:

<http://semmas.manaus.am.gov.br/wpcontent/uploads/2010/10/lei_pro_aguas.pdf >. Acesso em: 15 ago. 2015.

MARINGÁ. Lei $\mathbf{n}^{\mathbf{0}} \mathbf{6 . 3 4 5}$, de 15 de outubro de 2003. Disponível em:

https://www.leismunicipais.com.br/a/pr/m/maringa /lei-ordinaria/2003/635/6345/lei-ordinaria-n-63452003-institui-o-programa-de-reaproveitamento-deaguas-de-maringa. Acesso em: 12 ago. 2015.

MATÃO. Lei Municipal no 4.520, de 24 de julho de 2012. Disponível em:

https://www.leismunicipais.com.br/a/sp/m/matao/l ei-ordinaria/2012/452/4520/lei-ordinaria-n-4520-

2012-autoriza-a-utilizacao-do-sistema-de-reusode-agua-de-chuva-no-municipio-de-matao-parautilizacao-nao-potavel-em-condominios-clubesentidades-conjuntos-habitacionais-e-demaisimoveis-residenciais-industriais-e-comerciais-e-daoutras-providencias?q=4520 $>$. Acesso em: 15 jan. 2015.

PARAÍBA. Lei no 9.130 de 27, de maio de 2010. Disponível em:

<http://www.aesa.pb.gov.br/legislacao/leis/estadua 1/Lei_9130_10_uso_racional_agua_edificios.pdf $>$. Acesso em: 13 jul. 2015.

PONTA GROSSA. Decreto Municipal no 7.673, de 15 de agosto de 2013. Disponível em: <https://leismunicipais.com.br/a1/pr/p/pontagrossa/decreto/2013/768/7673/decreto-n-76732013-regulamenta-o-procedimento-administrativopara-o-programa-de-captacao-armazenamentoconservacao-e-uso-racional-da-agua-pluvial-nasedificacoes-urbanas-que-tenham-areaimpermeabilizada-igual-ou-superior-500-m2conforme-especifica?q=7673 >. Acesso em: 13 out. 2014.
PORTO ALEGRE. Decreto Municipal no 18.611, de 9 de abril de 2014. Disponível em: $<$ http://www2.portoalegre.rs.gov.br/cgi-bin/nphbrs? $\mathrm{u}=/$ netahtml/sirel/avancada.html $\& \mathrm{p}=1 \& \mathrm{r}=1 \& \mathrm{f}$ $=\mathrm{G} \& \mathrm{~d}=\mathrm{ATOS} \& \mathrm{l}=20 \& \mathrm{n}=-$

DATA\&s1=\&s2=\&s3=\%2218611\%22\&s4=\&s5= \&s6=>. Acesso em: 5 maio 2014.

PORTO ALEGRE. Lei $\mathbf{n}^{\mathbf{0}} \mathbf{1 0 . 5 0 6}$, de 5 de agosto de 2008. Disponível em:

<http://www2.portoalegre.rs.gov.br/cgi-bin/nphbrs?s1=000029949.DOCN.\&l=20\&u=/netahtml/sir $\mathrm{el} /$ simples.html\&p=1\&r=1\&f=G\&d=atos\&SECT1 $=$ TEXT $>$. Acesso: 2 mar. 2015.

RECIFE. Lei Municipal no 18.011, de 28 de abril de 2014. Disponível em:

<https://www.leismunicipais.com.br/a/pe/r/recife/l ei-ordinaria/2014/1802/18011/lei-ordinaria-n18011-2014-dispoe-sobre-a-politica-desustentabilidade-e-de-enfrentamento-dasmudancas-climaticas-do-recife-e-da-outrasprovidencias?q=18011>. Acesso em: 08 de ago. 2015.

RHINOPISOS. Rhinoverde: bloco de concreto intertravado. 2012. Disponível em: http://www.rhinopisos.com.br/site/produtos/3/rhin o-

verde_piso_grama_concregrama_pavimento_ecolo gico_permeavel_drenante_concreto. Acesso em: 12 nov. 2012.

\section{RIO DE JANEIRO. Decreto Municipal $\mathbf{n}^{\circ}$}

23.940, de 30 de janeiro de 2004. Disponível em: $<$ http://cm-rio-de-

janeiro.jusbrasil.com.br/legislacao/917561/decreto -23940-04>. Acesso em: 2 maio 2014.

RIVERSIDES. Vegeted Swales. 2012. Disponível em:

<http://www.riversides.org/rainguide/riversides_h gr.php cat $=2 \&$ page $=39 \&$ subpage $=92 \&$ subpage $2=$ 44>. Acesso em: 23 out. 2012.

SALVADOR. Lei $\mathbf{n}^{\mathbf{0}} \mathbf{7 . 8 6 3}$ de 25, de maio de 2010. Disponível:

<http://www.normasbrasil.com.br/norma/lei-78632010-salvador_178281.html>. Acesso em: 15 ago. 2015.

SANTA MARIA. Lei Complementar n⿳0 034, de 29 de dezembro de 2005. Disponível:

<https://www.santamaria.rs.gov.br/docs/leis/lc_03 4_plano_diretor.pdf>. Acessado em: 15 jul. 2012.

SANTA MARIA. Lei complementar $\mathbf{n}^{\mathbf{0}} \mathbf{0 7 2}$, de 4 de novembro de 2009. Disponível:

<http://www.santamaria.rs.gov.br/docs/leis/lm_72 _uso_solo.pdf >. Acesso em: 13 set. 2012. 
SANTOS, D. C. dos et al. Hierarquização de Medidas de Conservação de Água em Edificações Residenciais Com o Auxílio da Análise Multicritério. Ambiente Construído, Porto Alegre, v. 6, n. 1, p. 31-47, jan./mar. 2006.

SÃO PAULO. Lei Municipal $\mathbf{n}^{0} \mathbf{1 3 . 2 7 6}$, de 4 de janeiro de 2002. Disponível em:

$<$ http://www.aguaspluviais.inf.br/recomendacoes.a spx?id=5\&RecId=5>. Acesso em: 5 maio 2014.

SÃO PAULO. Lei Municipal no 14.459, de 3 de julho de 2007. Disponível em:

<http://http://www.leispaulistanas.com.br/sites/def ault/files/4ce1d5a3d9c3d3db858597d978e299f0.p df5>. Acesso em: 5 maio 2015.

SAUTCHÚCK, C. A. Formulação de Diretrizes Para Implantação de Programas de Conservação de Água em Edificações. São Paulo, 2004. 332 f. Dissertação (Mestrado em Engenharia Civil) - Escola Politécnica, Universidade de São Paulo, São Paulo, 2004.
STATE OF TENESSEE. Harnessing Rainwater. Departamento of Agriculture, 2012. Disponível em: <http://www.tn.gov/agriculture/article/agfarms-rainwater $>$. Acesso em: 21 nov. 2012.

TASSI, R. Efeito dos Microrreservatório de Lote Sobre a Macrodrenagem Urbana. Porto Alegre, 2002. 132 f. Dissertação (Mestrado em Engenharia Civil) - Programa de Pós-Graduação em Engenharia de Recursos Hídricos e Saneamento Ambiental, Universidade Federal do Rio Grande do Sul, Porto Alegre, 2002.

TUCCI, C. E. M. Aspectos Institucionais do Controle das Inundações Urbanas. In: TUCCI, C. E. M.; MARQUES, D. M. (Orgs.). Avaliação e Controle da Drenagem Urbana. Porto Alegre: Ed. da ABRH, 2001.

TUCCI, C. E. M.; PORTO, R. L. L.; BARROS, M. T. Drenagem Urbana. Porto Alegre: Ed. da UFRGS, 1995.

WAVERLEY COUNCIL. Water Management: technical manual. Waverley, 2014.

WOODS-BALLARD, B. et al. SuDS Manual. London: Construction Industry Research and Information Association, 2007.

Rutinéia Tassi

Departamento de Egenharia Sanitária e Ambiental, Centro de Tecnologia | Universidade Federal de Santa Maria | Av. Roraima, 1000, Cidade Universitária, Camobi | Santa Maria - RS - Brasil | CEP 97105-900 | Tel.: (55) 3220-6153 | E-mail: rutineia@gmail.com

Daniel Gustavo Allasia Piccilli

Departamento de Egenharia Sanitária e Ambiental, Centro de Tecnologia | Universidade Federal de Santa Maria |

E-mail: dallasia@gmail.com

Santiago Chaves Brancher

Engenharia Civil, Centro de Tecnologia | Universidade Federal de Santa Maria | E-mail: santiagobrancher@hotmail.com

Carlos Augusto Roman

Programa de Pós-graduação em Engenharia Civil, Centro deTecnologia | Universidade Federal de Santa Maria | Tel.: (55) 3222-0848 | Email: carlosaugustoroman@gmail.com

Revista Ambiente Construído

Associação Nacional de Tecnologia do Ambiente Construído

Av. Osvaldo Aranha, $99-3^{\circ}$ andar, Centro

Porto Alegre - RS - Brasil

CEP $90035-190$

Telefone: +55 (51) 3308-4084

Fax: +55 (51) 3308-4054

www.seer.ufrgs.br/ambienteconstruido

E-mail: ambienteconstruido@ufrgs.br

52 Tassi, R.; Allasia Piccilli, D. G.; Brancher, S. C.; Roman, C. A. 